\title{
The sensitivity and specificity of methylene blue spray to identify the parathyroid gland during thyroidectomy
}

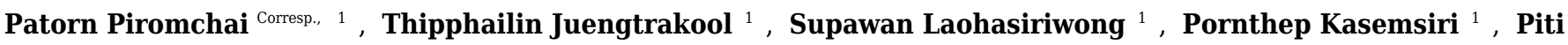 \\ Ungarereevittaya $^{2}$ \\ 1 Department of Otorhinolaryngology, Faculty of Medicine, Khon Kaen University, Khon Kaen, Thailand \\ 2 Department of Pathology, Faculty of Medicine, Khon Kaen University, Khon Kaen, Thailand \\ Corresponding Author: Patorn Piromchai \\ Email address: patorn@kku.ac.th
}

Background: Hypocalcemia is a common complication of thyroidectomy resulting from an injury to the parathyroid gland. Methylene blue, which is a medication and dye that has been used for more than a century, is safe and readily available. The previous study has found that methylene blue spray on the surgical field is absorbed by the parathyroid gland faster than in the perithyroidal area. This study was aimed to evaluate the diagnostic value of methylene blue spray to identify the parathyroid gland during thyroid lobectomy.

Methods: Patients who underwent thyroid lobectomy were recruited. After the recurrent laryngeal nerve was identified, methylene blue was sprayed onto the thyroid bed. After five minutes, the thyroid bed was inspected for areas in which the blue color had been rapidly absorbed. Biopsies were conducted for histopathology at both the stained area and the area in which the color had faded. The sensitivity, specificity, positive predictive value (PPV), and negative predictive value (NPV) were calculated. Results: Forty-seven patients participated in this study. The sensitivity of methylene blue spray to identify the parathyroid gland during thyroid lobectomy was $92.31 \%(95 \% \mathrm{Cl}=63.97$ to 99.81$)$ and specificity was $56.79 \%(95 \% \mathrm{Cl}=45.31$ to 67.76$)$. The PPV was $25.53 \%$ (95\% Cl $=20.34$ to $31.53)$ and NPV was $97.87 \%(95 \% \mathrm{Cl} 87.39$ to 99.67$)$. There were no patients with postoperative hypocalcemia, allergic reactions to the methylene blue, or methylene blue toxicity. Conclusion: The methylene blue spray could serve as a screening tool for identification of the parathyroid gland. 


\title{
1 The sensitivity and specificity of methylene blue spray
} 2 to identify the parathyroid gland during thyroidectomy

3

4 5 6

\author{
Patorn Piromchai ${ }^{1}$, Thipphailin Juengtrakoo ${ }^{1}$, Supawan Laohasiriwong ${ }^{1}$, Pornthep Kasemsiri ${ }^{1}$, \\ Piti Ungarereevittaya ${ }^{2}$ \\ ${ }^{1}$ Department of Otorhinolaryngology, Faculty of Medicine, Khon Kaen University, Khon Kaen, \\ Thailand \\ ${ }^{2}$ Department of Pathology, Faculty of Medicine, Khon Kaen University, Khon Kaen, Thailand.
}

Corresponding Author:

Patorn Piromchai ${ }^{1}$

Department of Otorhinolaryngology, Faculty of Medicine, Khon Kaen University, Khon Kaen, 40002, Thailand

Email address: patorn@kku.ac.th

\section{Abstract}

Background: Hypocalcemia is a common complication of thyroidectomy resulting from an injury to the parathyroid gland. Methylene blue, which is a medication and dye that has been used for more than a century, is safe and readily available. The previous study has found that methylene blue spray on the surgical field is absorbed by the parathyroid gland faster than in the perithyroidal area. This study was aimed to evaluate the diagnostic value of methylene blue spray to identify the parathyroid gland during thyroid lobectomy.

Methods: Patients who underwent thyroid lobectomy were recruited. After the recurrent laryngeal nerve was identified, methylene blue was sprayed onto the thyroid bed. After five minutes, the thyroid bed was inspected for areas in which the blue color had been rapidly absorbed. Biopsies were conducted for histopathology at both the stained area and the area in which the color had faded. The sensitivity, specificity, positive predictive value (PPV), and negative predictive value (NPV) were calculated.

Results: Forty-seven patients participated in this study. The sensitivity of methylene blue spray to identify the parathyroid gland during thyroid lobectomy was $92.31 \%(95 \% \mathrm{CI}=63.97$ to 99.81$)$ and specificity was $56.79 \%(95 \% \mathrm{CI}=45.31$ to 67.76$)$. The $\mathrm{PPV}$ was $25.53 \%(95 \% \mathrm{CI}=20.34$ to 31.53 ) and NPV was $97.87 \%$ (95\% CI 87.39 to 99.67$)$. There were no patients with postoperative hypocalcemia, allergic reactions to the methylene blue, or methylene blue toxicity.

Conclusion: The methylene blue spray could serve as a screening tool for identification of the parathyroid gland. 
40

41

42

43

44

45

46

47

48

49

50

51

52

53

54

55

56

57

58

59

60

61

62

63

64

65

66

67

68

69

70

71

72

73

74

75

76

77

78

\section{Introduction}

Post-operative hypocalcemia is the most frequently encountered complication after thyroidectomy. The incidence of transient hypocalcemia has been shown to be $7-36 \%$, and that of permanent hypocalcemia to be $15 \%$ post thyroidectomy (Pattou et al. 1998).

Hypocalcemia after thyroidectomy is caused by direct injury to the parathyroid gland or injury to its blood supplies (Reeve \& Thompson 2000). Post-operative hypocalcemia affects the physical and psychological health of the patient and lengthens hospital stay. Hypocalcemia can be present with peri-oral numbness, numbness of the fingertips and positive of Chvostek's sign. There may be muscle spasms, cramping, seizures, or cardiac arrhythmia in severe cases. Treatment of hypocalcemia consists of giving patients calcium supplements and vitamin D (Falk et al. 1988).

Current guidelines for prevention of parathyroid thyroid injury during thyroid surgery is by anatomically locating the parathyroid gland. However, this gland is difficult to separate from the surrounding fat and lymph nodes, which is a reason that post-operative hypocalcemia still occurs.

Other methods to identify the parathyroid gland during thyroidectomy include a partial biopsy of the gland for pathological examination (Anton \& Wheeler 2005), intravenous methylene blue injection (Bewick \& Pfleiderer 2014), computerized tomography during thyroid surgery (Sommerey et al. 2015), parathyroid specific luminescence (Suzuki et al. 2011), fine needle aspiration for an analysis of parathyroid hormone levels (Huang et al. 2013).

Methylene blue, which is a medication and dye that has been used more than a century, is safe and readily available. A previous case series found that methylene blue spray on the surgical field was absorbed by the parathyroid gland faster than in the surrounding perithyroidal area (Sari et al. 2012). This study was aimed at evaluating the diagnostic value of methylene blue spray in identifying the parathyroid gland during thyroidectomy.

\section{Materials \& Methods}

\section{Study design and setting}

This prospective diagnostic study was conducted from July 2016 to April 2018 at the Khon Kaen University, Faculty of Medicine, Department of Otorhinolaryngology, Thailand.

The inclusion criteria were patients aged 18 years or older and underwent thyroid lobectomy. Exclusion criteria were previous thyroid surgery, methylene blue allergies, renal diseases, G6PD deficiency, pregnancy, and having received monoamine oxidase inhibitors such as tranylcypromine, isocarboxazid, phenelzine, furazolidone, isoniazid, procarbazine, or linezolid.

Recurrent laryngeal nerve function, thyroid hormone levels, and calcium levels were preand post-operatively evaluated. All participants underwent open thyroidectomy under general anesthesia.

During thyroidectomy, the thyroid gland was pulled back to identify the recurrent laryngeal nerve and upper and lower parathyroid glands. One milliliter $(10 \mathrm{mg})$ of $1 \%$ methylene blue solution was sprayed over the thyroid bed and perithyroidal tissue (Figure 1). Five minutes after 
91

92

93

94

95

96

97

98

99

100

101

102

103

104

105

106

107

108

109

110

111

112

113

114

115

116

117

118

spraying, parathyroid glands had absorbed the blue stain and regained their original yellow color. Other tissues were still stained blue (Figure 1-3).

The biopsies were conducted at 1) the area that was suspected to be the parathyroid gland based on surgical anatomy, which had regained its yellow color and 2) the blue-stained area that was not suspected to be the parathyroid gland. An incisional biopsy of $2 \mathrm{~mm}$ diameter for each specimen was performed carefully to prevent an injury to a recurrent laryngeal nerve or thyroid gland by consultant otolaryngologists or under their supervision.

The two specimens from each patient were submitted for histopathology. To blind the pathologist, a computer-generated randomization list was used. The specimens were randomly labeled as either specimen "A" or "B".

The patients received standard post-operative care. The postoperative complications and duration of hospital stay were recorded.

\section{Statistical analysis}

The sample size was calculated using an estimated sensitivity of 70 percent with a range of sensitivity from 60 to 80 percent. With a significance level of 0.5 and power of 90 percent, the total number of specimens required were determined to be 81 .

The categorical variables were presented in the form of frequencies and percentages. The associations among categorical variables were assessed using a chi-square test. The continuous variables were presented in the form of means. The sensitivity, specificity, positive predictive value (PPV), and negative predictive value (NPV) were calculated with a 95\% confident interval.

\section{Ethical considerations}

This study was approved by the Khon Kaen University Ethics Committee in Human Research (HE591169) and registered in the Thai Clinical Trials Registry (TCTR20160726003). Written informed consent to participate in this study was provided by all patients enrolled.

\section{Results}

Forty-seven patients participated in this study, six of whom were male (13.33\%) and 41 of whom were female $(86.67 \%)$. The average age of the patients was 50.30 years old (ranging from 22 to 81 years old). Pre-operative diagnoses were as follows: unilateral nontoxic single thyroid nodule $(n=43)$, thyroid toxic adenoma $(n=1)$, Grave's disease with cold nodule $(n=3)$. The cytology from fine needle aspiration were non-diagnosis $(\mathrm{n}=19)$, benign follicular nodule $(\mathrm{n}=$ $17)$, follicular cell neoplasm $(n=3)$, and atypia of undetermined significance $(n=8)$. The size of thyroid nodule according to physical examination was between 1 to $10 \mathrm{~cm}$ (average $3.83 \pm 1.77$ $\mathrm{cm})$. (Table 1)

Twelve of the 47 specimens that were positive for rapid wash-out were confirmed to be parathyroid tissue by histopathology. Thirty-four were fibrofatty tissue, and one was a lymph node. Conversely, only one of the 47 negative specimens were found to be parathyroid tissue, while the remaining 46 were found to be fibrofatty tissue. (Table 2) 
Sensitivity of methylene blue spray to identify the parathyroid gland during thyroidectomy was $92.31 \%(95 \% \mathrm{CI}=63.97$ to 99.81$)$ and specificity was $56.79 \%(95 \% \mathrm{CI}=45.31$ to 67.76$)$. The PPV was $25.53 \%$ (95\% CI $=20.34$ to 31.53 ) and NPV was $97.87 \%$ (95\% CI 87.39 to 99.67$)$.

Histopathology results of the thyroid nodules were as follows: follicular adenoma $(n=38)$, papillary thyroid carcinoma $(n=3)$, Hurthle cell adenoma $(n=4)$, degenerative cyst $(n=1)$ and chronic thyroiditis $(n=1)$. Patients were discharged after an average of 3.38 days $(3-5$ days $)$ with no major complications (no signs or symptoms of postoperative hypocalcemia, no post-operative vocal cord immobility, and no post-operative hematoma). None of the patients had allergic reactions to the methylene blue or methylene blue toxicity.

\section{Discussion}

There have been various methods proposed to identify the parathyroid gland in order to decrease the incidence of postoperative hypocalcemia. We summarized the advantages and disadvantages of each method in Table 3 .

Methylene blue is certified by the US Food and Drug Administration. It can be used in a variety of medical treatments, including hereditary methemoglobinemia, acute acquired methemoglobinemia, prevention of urinary tract infection in the elderly, and localization of nerves and endocrine tissues. There are few side effects associated with methylene blue. However, toxicity can occur if more than $5 \mathrm{mg} / \mathrm{kg}$ is used. Symptoms of toxicity include dizziness, nausea, vomiting, headache, abdominal pain, and confusion (Schirmer et al. 2011), (Oz et al. 2011), (Gillman 2006).

Sari (Sari et al. 2012) studied 56 patients who underwent thyroidectomy in which methylene blue spray was used to locate the parathyroid gland. They found that the parathyroid gland was able to absorb the blue staining and regain its original yellow color in three minutes, while other tissues took longer. They found that the thyroid took 15 minutes and fat, tendon, and muscle took more than 25 minutes. They proposed the theory that parathyroid glands can absorb methylene blue faster than other tissues because they have a dense lymphovascular pattern.

In this study, we further evaluated the diagnostic value of methylene blue spray. The sensitivity of spraying methylene blue was $92.31 \%(95 \% \mathrm{CI}=63.97$ to 99.81$)$ and specificity was $56.79 \%$ (95\% CI $=45.31$ to 67.76$)$. The PPV was $25.53 \%(95 \% \mathrm{CI}=20.34$ to 31.53$)$ and NPV was $97.87 \%$ (95\% CI 87.39 to 99.67 ). Our result found that methylene blue spray at thyroid bed to identify the parathyroid gland was highly sensitive and suitable to use as a screening tool to avoid injury to the parathyroid gland.

To achieve this high sensitivity, the surgeon needs to identify the area suspected to be parathyroid gland first and confirms by methylene blue spray. Solely use of methylene blue spray without surgical skills and knowledge was highly not recommended.

In all of our cases, we can observe the difference of blue shading between the suspected area and another area. However, in an unexpected situation, the surgeon may feel uncertain of the 
158

159

160

161

162

163

164

165

166

167

168

169

170

171

172

173

174

175

176

177

178

179

180

181

182

183

184

185

186

187

188

189

190

191

192

193

194

195

196

197

198

199

shading. In this case, we recommended using an additional tool such as fine-needle aspiration (FNA) with measurement of parathyroid hormone levels to identify parathyroid gland.

To our knowledge, this is the first diagnostic study to evaluate the value of methylene blue spray to identify parathyroid gland. The results of this study can be applied in order to help to identify the parathyroid gland during thyroidectomy and may decrease postoperative hypocalcemia.

\section{Conclusions}

The methylene blue spray could serve as a screening tool for identification of the parathyroid gland.

\section{Acknowledgements}

The authors would like to thank the staff and nurses at Srinagarind Hospital for their excellent care of the patients.

\section{References}

Anton RC, and Wheeler TM. 2005. Frozen section of thyroid and parathyroid specimens. Archives of Pathology and Laboratory Medicine 129:1575-1584.

Bewick J, and Pfleiderer A. 2014. The value and role of low dose methylene blue in the surgical management of hyperparathyroidism. Annals of the Royal College of Surgeons of England 96:526-529. 10.1308/003588414X13946184903883

Falk SA, Birken EA, and Baran DT. 1988. Temporary postthyroidectomy hypocalcemia. Archives Of Otolaryngology--Head \& Neck Surgery 114:168-174.

Gillman PK. 2006. Methylene blue implicated in potentially fatal serotonin toxicity. Anaesthesia 61:1013-1014.

Huang H-y, Li H, Lin S-j, Deng W-y, Li Q-1, Chen Y-f, Yang A-k, Zhang Q, and Guo Z-m. 2013. [Fine-needle aspiration with measurement of parathyroid hormone levels in thyroidectomy]. Zhonghua Er Bi Yan Hou Tou Jing Wai Ke Za Zhi = Chinese Journal Of Otorhinolaryngology Head And Neck Surgery 48:934-938.

Kapre M. 2009. Preservation of the Parathyroids in Thyroid Surgery. World Articles in Ear, Nose and Throat 2.

Oz M, Lorke DE, Hasan M, and Petroianu GA. 2011. Cellular and molecular actions of Methylene Blue in the nervous system. Medicinal Research Reviews 31:93-117. 10.1002/med.20177

Pattou F, Combemale F, Fabre S, Carnaille B, Decoulx M, Wemeau JL, Racadot A, and Proye C. 1998. Hypocalcemia following thyroid surgery: incidence and prediction of outcome. World Journal of Surgery 22:718-724.

Reeve T, and Thompson NW. 2000. Complications of thyroid surgery: how to avoid them, how to manage them, and observations on their possible effect on the whole patient. World Journal of Surgery 24:971-975.

Sari S, Aysan E, Muslumanoglu M, Ersoy YE, Bektasoglu H, and Yardimci E. 2012. Safe thyroidectomy with intraoperative methylene blue spraying. Thyroid Research 5:15-15. $10.1186 / 1756-6614-5-15$ 
200 Schirmer RH, Adler H, Pickhardt M, and Mandelkow E. 2011. "Lest we forget you--methylene 201 blue...". Neurobiology of 32:2325.e2327-2316. $202 \quad$ 10.1016/j.neurobiolaging.2010.12.012

203 Sommerey S, Al Arabi N, Ladurner R, Chiapponi C, Stepp H, Hallfeldt KKJ, and Gallwas JKS. 204 2015. Intraoperative optical coherence tomography imaging to identify parathyroid glands. $205 \quad$ Surgical Endoscopy 29:2698-2704. 10.1007/s00464-014-3992-x

206 Suzuki T, Numata T, and Shibuya M. 2011. Intraoperative photodynamic detection of normal 207 parathyroid glands using 5-aminolevulinic acid. The Laryngoscope 121:1462-1466. $208 \quad 10.1002 /$ lary. 21857 
Table $\mathbf{1}$ (on next page)

Patient characteristics 
1 Table 1. Patient characteristics

\begin{tabular}{|c|c|c|}
\hline \multicolumn{2}{|l|}{ Characteristics } & $\mathbf{N}(\%)$ \\
\hline \multicolumn{2}{|l|}{ Age (min-max) } & $50(22-81)$ \\
\hline \multicolumn{2}{|l|}{ Male } & $6(12.77 \%)$ \\
\hline \multicolumn{2}{|l|}{ Female } & $41(87.23 \%)$ \\
\hline \multirow[t]{3}{*}{ Pre-operative diagnosis } & Nontoxic single thyroid nodule & $43(91.15 \%)$ \\
\hline & Grave's disease with cold nodule & $3(6.38 \%)$ \\
\hline & Thyroid toxic adenoma & $1(2.13 \%)$ \\
\hline \multirow[t]{4}{*}{ Pre-operative cytology } & Non-diagnostic & $19(39.60 \%)$ \\
\hline & Benign follicular nodule & $17(35.40 \%)$ \\
\hline & Follicular cell neoplasm & $3(6.30 \%)$ \\
\hline & Atypia of undetermined significant & $8(16.70 \%)$ \\
\hline \multicolumn{2}{|c|}{ Size of thyroid nodule $(\mathrm{cm})$} & $3.83 \pm 1.77$ \\
\hline
\end{tabular}

2 
Table 2 (on next page)

Diagnostic value of methylene blue spray 
1 Table 2. Diagnostic value of methylene blue spray

\begin{tabular}{|c|c|c|}
\hline \multirow{2}{*}{$\begin{array}{l}5 \text { Minutes after methylene } \\
\text { blue spray }\end{array}$} & \multicolumn{2}{|c|}{ Histopathology } \\
\hline & $\begin{array}{c}\text { Positive for parathyroid } \\
\text { gland }(\mathrm{n}=13)\end{array}$ & $\begin{array}{l}\text { Negative for parathyroid } \\
\text { gland }(n=81)\end{array}$ \\
\hline Rapid wash-out $(n=47)$ & 12 & 35 \\
\hline Stained blue $(\mathrm{n}=47)$ & 1 & 46 \\
\hline
\end{tabular}

2

3 


\section{Table 3 (on next page)}

Methods to identify the parathyroid gland 
1 Table 3. Methods to identify the parathyroid gland

\begin{tabular}{|c|c|c|}
\hline Methods & Advantages & Disadvantages \\
\hline $\begin{array}{l}\text { 1. Frozen section (Anton } \\
\text { \& Wheeler 2005) }\end{array}$ & $\begin{array}{l}\text { - Close to gold standard. } \\
\text { - Accuracy more than } 99 \% \text {. }\end{array}$ & - Used only in parathyroid diseases. \\
\hline $\begin{array}{l}\text { 2. Surgical anatomy of } \\
\text { the superior and } \\
\text { inferior thyroid } \\
\text { arteries (Kapre 2009) }\end{array}$ & - Low cost. & $\begin{array}{l}\text { - Post-operative } \\
\text { hypoparathyroidism still occurs in } \\
\text { around } 10 \% \text { of cases. }\end{array}$ \\
\hline $\begin{array}{l}\text { 3. Intraoperative optical } \\
\text { coherence } \\
\text { tomography imaging } \\
\text { (Sommerey et al. } \\
\text { 2015) }\end{array}$ & & $\begin{array}{l}\text { - An accurate differentiation } \\
\text { between parathyroid tissue and } \\
\text { lymph nodes was not possible. } \\
\text { - High cost. }\end{array}$ \\
\hline $\begin{array}{ll}\text { 4. } & \text { Intravenous } \\
\text { methylene blue } \\
\text { injection (Bewick \& } \\
\text { Pfleiderer 2014) }\end{array}$ & - Low cost. & $\begin{array}{l}-78.6 \% \text { of cases stained positively } \\
\text { with methylene blue. } \\
\text { - } 5.8 \% \text { of patients suffer from a } \\
\text { systemic complication of methylene } \\
\text { blue injection. }\end{array}$ \\
\hline $\begin{array}{l}\text { 5. Intraoperative } \\
\text { photodynamic } \\
\text { detection of } \\
\text { normal parathyroid } \\
\text { glands using 5-ALA } \\
\text { (Suzuki et al. 2011) }\end{array}$ & - 100\% specificity. & $\begin{array}{l}\text { - High cost, long test duration and } \\
\text { not available in all hospitals. } \\
\text { - Side effects: four patients had } \\
\text { nausea and two had to vomit. }\end{array}$ \\
\hline $\begin{array}{l}\text { 6. FNA with } \\
\text { measurement of } \\
\text { parathyroid hormone } \\
\text { levels in } \\
\text { thyroidectomy } \\
\text { (Huang et al. 2013) } \\
\end{array}$ & $\begin{array}{l}-97.8 \% \text { sensitivity and } \\
100 \% \text { specificity. }\end{array}$ & $\begin{array}{l}\text { - High cost and not available in all } \\
\text { hospitals. }\end{array}$ \\
\hline $\begin{array}{l}\text { 7. Intraoperative } \\
\text { methylene blue spray }\end{array}$ & $\begin{array}{l}\text { - 92.31\% sensitivity } \\
\text { - Safe, rapid, easy, and low } \\
\text { cost. }\end{array}$ & \\
\hline
\end{tabular}

2 


\section{Figure 1}

Before spraying of methylene blue

$\mathrm{T}$ - thyroid gland; R - recurrent laryngeal nerve; P - parathyroid gland.

Photo credit: Patorn Piromchai, MD, MSc, PhD, FRCOT, FICS.

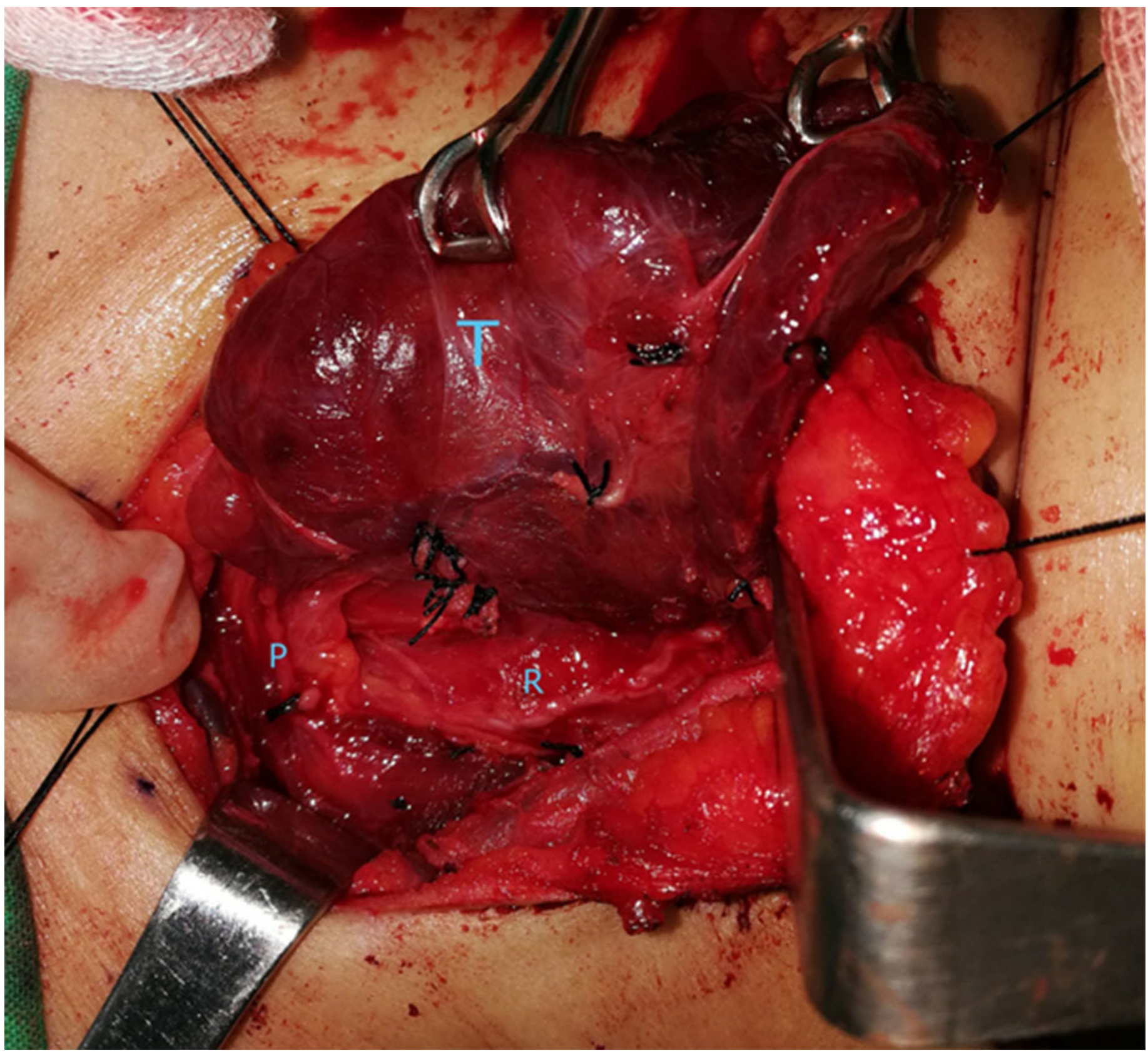




\section{Figure 2}

Immediately after spraying of methylene blue.

$\mathrm{T}$ - thyroid gland; R - recurrent laryngeal nerve; $\mathrm{P}$ - parathyroid gland.

Photo credit: Patorn Piromchai, MD, MSc, PhD, FRCOT, FICS.

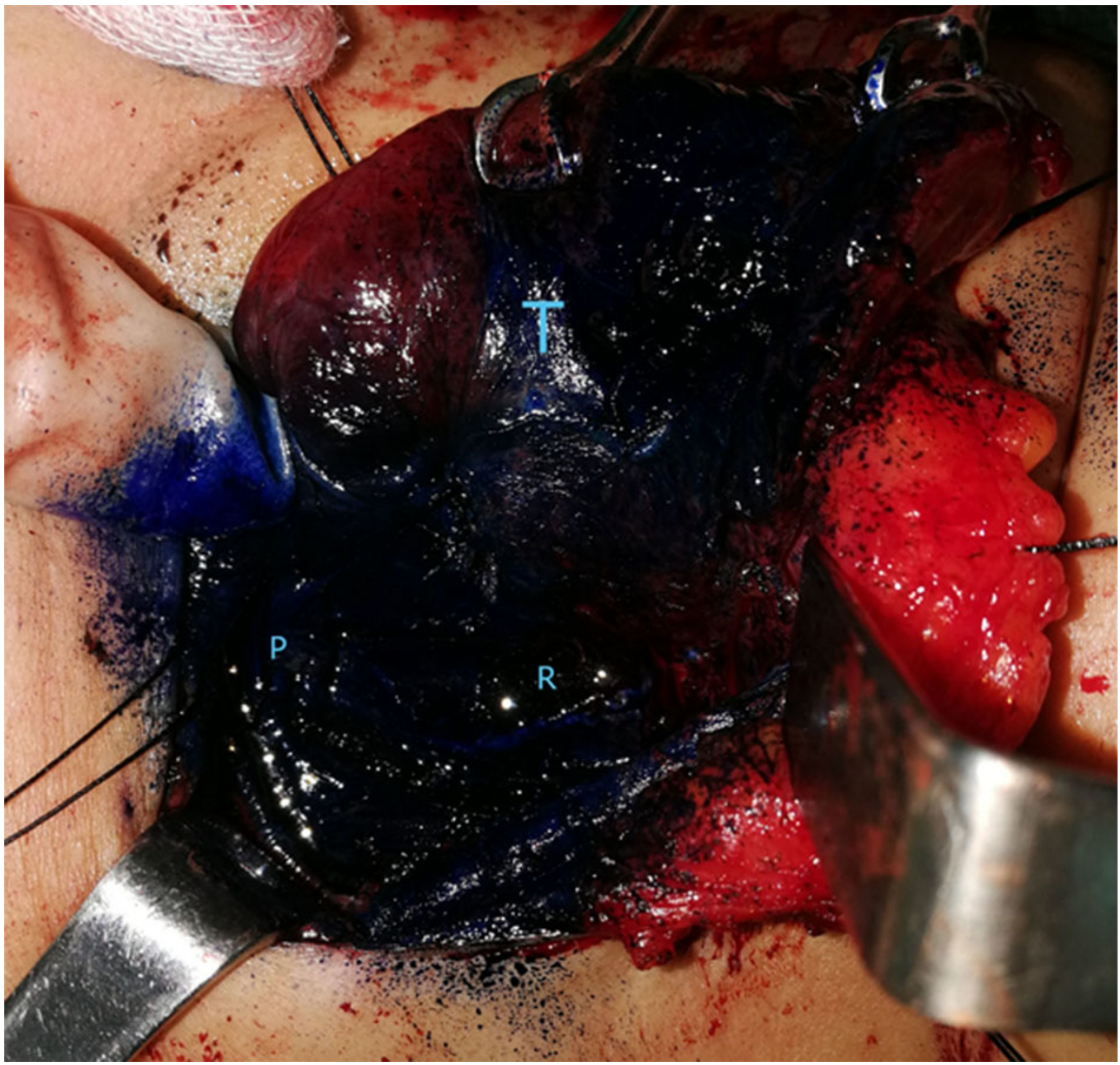




\section{Figure 3}

Five minutes after spraying of methylene blue.

$\mathrm{T}$ - thyroid gland; R - recurrent laryngeal nerve; $\mathrm{P}$ - parathyroid gland.

Photo credit: Patorn Piromchai, MD, MSc, PhD, FRCOT, FICS.

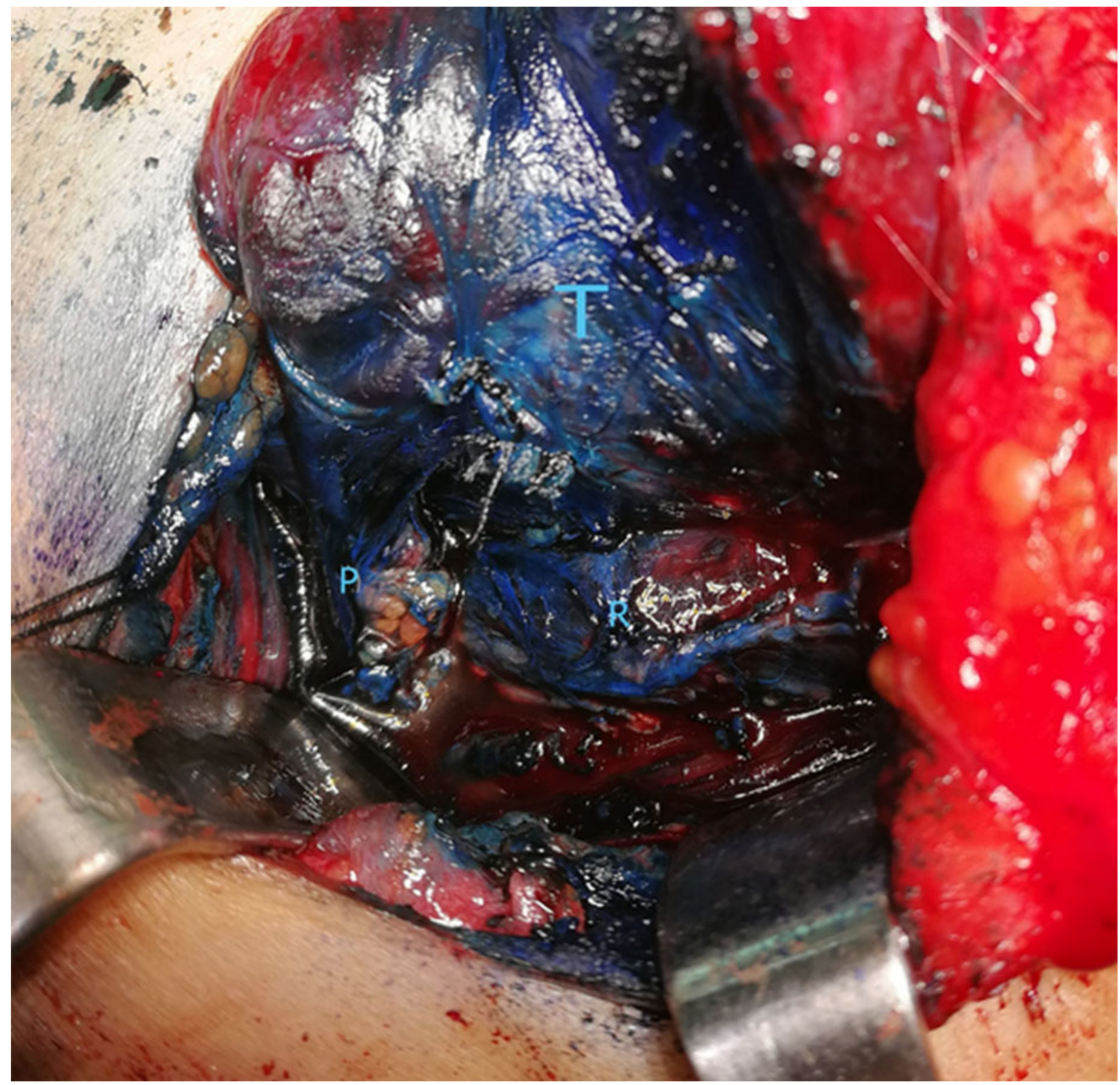

